\title{
First Description of Migratory Behavior of Humpback Whales From an Antarctic Feeding Ground to a Tropical Breeding Ground
}

\section{Michelle Modest ( $\nabla$ mmodest@ucsc.edu )}

University of California Santa Cruz https://orcid.org/0000-0001-9174-7414

\section{Ladd Irvine}

Oregon State University Hatfield Marine Science Center

\section{Virginia Andrews-Goff}

Australian Antarctic Division

\section{William Gough}

Stanford University Hopkins Marine Station

\section{David Johnston}

Duke University Marine Laboratory

\section{Douglas Nowacek}

Duke University Marine Laboratory

\section{Logan Pallin}

University of California Santa Cruz

\section{Andrew Read}

Duke University Marine Laboratory

Reny Tyson Moore

Chicago Zoological Society

\section{Ari Friedlaender}

University of California Santa Cruz

\section{Research Article}

Keywords: Humpback migration, animal movement models, HSSM, Animal Ecology, Conservation, Humpback whales, Antarctica

Posted Date: February 15th, 2021

DOl: https://doi.org/10.21203/rs.3.rs-224086/v1

License: (c) (1) This work is licensed under a Creative Commons Attribution 4.0 International License. 



\section{First Description of Migratory Behavior of Humpback}

\section{Breeding Ground}

5 Michelle Modest ${ }^{1}$, Ladd Irvine ${ }^{2}$, Virginia Andrews-Goff ${ }^{3}$, William Gough ${ }^{4}$, David Johnston ${ }^{5}$,

6 Douglas Nowacek ${ }^{5}$, Logan Pallin ${ }^{1}$, Andrew Read ${ }^{5}$, Reny Tyson Moore ${ }^{6}$, Ari Friedlaender ${ }^{1}$

1. Department of Ecology and Evolutionary Biology, UC Santa Cruz, Santa Cruz,

9 CA, USA

10 2. Marine Mammal Institute and Department of Fisheries and Wildlife, Hatfield

11 Marine Science Center, Oregon State University, Newport, OR, USA

12 3. Australian Marine Mammal Centre, Australian Antarctic Division, Kingston,

13 Tasmania, Australia

14 4. Department of Biology, Hopkins Marine Station, Stanford University, Monterey, $15 \quad$ CA, USA

16 5. Duke University Marine Laboratory, Duke University, Beaufort, North Carolina,

$17 \quad$ USA

18 6. Chicago Zoological Society's Sarasota Dolphin Research Program, Sarasota, FL, 19 USA 
ABSTRACT

21 Background: Despite exhibiting one of the longest migrations in the world, half of the

22 humpback whale migratory cycle has remained unexamined; until this point, no study has

23 provided a continuous description of humpback whale migratory behavior from a feeding ground

24 to a breeding ground. We present new information on the satellite derived offshore migratory

25 movements of 16 humpback whales from Antarctic feeding grounds to South American breeding

26 grounds. Satellite locations were used to demonstrate migratory corridors, while the impact of

27 departure date on migration speed was assessed using a linear regression, and a Bayesian

28 hierarchical state-space animal movement model was utilized to investigate the presence of

29 feeding behavior en route.

30 Results: 35,642 Argos locations from 16 tagged whales from 2012-2017 were collected. The 16

31 whales were tracked for an average of 38.5 days of migration (range 10-151 days). The length of

32 individually derived tracks ranged from 645-6,381 km. Humpbacks were widely dispersed

33 geographically during the initial and middle stages of their migration but convened in two bottleneck

34 regions near the southernmost point of Chile as well as Peru's Illescas Peninsula. The state space

35 model found almost no instances of ARS, a proxy for feeding behavior, along the migratory route.

36 The linear regression assessing whether departure date affected migration speed found suggestive

37 but inconclusive support for a positive trend between the two variables. No clear stratification by

38 sex or reproductive status, either in migration speed, departure date, or route choice, was found.

39 Conclusions: Southern hemisphere humpback whale populations are recovering quickly from

40 intense commercial whaling and, around the Antarctic Peninsula, are doing so in the face of a

41 rapidly changing environment. The current lack of scientific knowledge on marine mammal

42 migration is a major barrier to cetacean conservation. This multi-year study sets a baseline

43 against which the effects of climate change on humpback whales can be studied across years and 
44 conditions and provides an excellent starting point for the investigation into humpback whale

45 migration.

46

47 KEYWORDS

48 Humpback migration, animal movement models, HSSM, Animal Ecology, Conservation, Humpback

49 whales, Antarctica

\section{INTRODUCTION}

Humpback whale (Megaptera novaeangliae) migrations, with recorded one-way

53 distances of up to $8461 \mathrm{~km}$, are part of an annual cycle consisting of journeys between tropical

54 calving grounds in winter and high latitude feeding grounds in summer $(1,2)$. Baleen whale

55 migrations are considered a response to the need to feed in cold waters and reproduce in warm

56 waters $(1,2)$. Currently, NOAA recognizes 14 distinct populations of humpback whales, based on

57 breeding ground location, with seven in the Southern Hemisphere (3). These seven distinct

58 population segments (DPS) are found distributed around lower latitude coastal regions in the

59 Atlantic, Indian, and Pacific Ocean and rely on highly productive seasonal habitats in the

60 Antarctic, with several populations utilizing the Western Antarctic Peninsula, one of the most

61 rapidly warming areas in the world, as their foraging ground (4-6).

63 breeding and calving purposes year after year. In the foraging grounds, the whales disperse

64 somewhat more broadly than in the breeding grounds, but with only limited overlap and

65 intermingling between populations that breed in different geographic areas (7). The population 
66 breeding off the western coast of South America is the Southeastern Pacific DPS. Historically,

67 these animals have been recorded crossing the equator into waters off Colombia, but in recent

68 years, individuals from the Southeastern Pacific DPS have also been found further north off

69 Panama and Costa Rica, in regions frequented by northern humpback populations $(2,8)$.

70 Breeding behavior has been observed as early as June, peaking between August and October.

71 Specific calving sites have been documented in the nearshore waters off Colombia and Ecuador

72 (9). A 2020 study noted that the average date of arrival for individuals of the Southeastern DPS

73 in the breeding grounds in Gorgona National Park, Columbia, was the last week of May (10). As

74 of 2011, abundance estimates for the Southeastern Pacific DPS were around 6,500 (11).

Migratory Behavior

Despite the humpback whale's status as one of the longest migrating species on the

78 planet, little concrete information is known about their migration. As with most migratory

79 species, the difficulty of consistently tracking migratory behaviors means that research on

80 humpback whales has historically been biased toward the breeding and foraging areas. No

81 published study has examined the day to day movements of humpback whales on their migration

82 from foraging to breeding grounds - the only knowledge regarding this leg of migration

83 inferred from historical whaling and sighting data. More information exists for the journey from

84 breeding to foraging grounds, but most of this knowledge is from historical whaling data, with

85 limited contributions from a handful of recent small-scale studies.

86 Estimation of rate of movement from whaling records indicated relatively constant mean

87 southbound to northbound migratory speeds of $15^{\circ}$ per month, and an approximate Southern

88 Hemisphere migration duration of two to four months $(7,12)$. Aerial observations of individuals 
89 found substantial individual variation in migration rates over short periods and recorded speeds

90 ranging from 4.8 to $13 \mathrm{~km} \mathrm{~h}^{-1}$ over the course of a few hours (7). Recent satellite tag studies of

91 longer duration have recorded mean migration rates of $4.21 \pm 1.3 \mathrm{~km} \cdot \mathrm{h}^{-1}$ for North Atlantic

92 humpback whales migrating from the Antillean Island chain to Canada, the Gulf of Maine, and

93 the Eastern North Atlantic (13), $4.5 \mathrm{~km} \cdot \mathrm{h}^{-1}$ for humpback whales traveling from Hawai'i to

94 Alaska (14), and 3.83 and $3.48 \mathrm{~km} \cdot \mathrm{h}^{-1}$ for humpbacks migrating from Brazil to Antarctica and

95 South Georgia $(15,16)$.

It is thought that migratory timing and route are heavily influenced by sex, reproductive

97 status, and age of the animals (7,17-21). Felix and Guzman found that mothers with calves

98 preferred a coastal route, while single adults tended more towards open waters (21). Historical

99 whaling data for all southern hemisphere postwar land whaling stations indicates that females at

100 the end of lactation are the earliest group to leave the Antarctic, followed by immature whales,

101 mature males, resting females, and pregnant females (with start dates of twelve, twenty, twenty-

102 three, and thirty-one days later, respectively). Migratory triggers are unknown but are thought to

103 be environmental - such as daylight hours, sea ice formation, and prey abundance - or inherently

104 biological - such as hormone or body condition-based $(1,7)$. Dawbin hypothesized that the most

105 likely environmental trigger was daylight and that the entire cycle depended on seasonal changes

106 in Antarctic waters, as there is little fluctuation in daylight and temperature in the temperate

107 breeding grounds (7). Since departure dates from foraging grounds and arrival into breeding

108 grounds reported from whaling records and photo IDs $(7,20)$ are segregated along sex,

109 reproductive status, and age classes, it seems reasonable to hypothesize that marked differences

110 in average migration speed among groups exist. However, to our knowledge, this has only been

111 investigated in looking at females with calves vs single adults $(13,21)$. 
113 reserves accumulated in the foraging grounds (7,18). Dawbin (1966)'s investigation of thousands

114 of historical whaling records indicated that whales caught in warm waters had empty stomachs.

115 However, recent studies of humpback migration of various DPS's from breeding to foraging

116 grounds have shown that some animals do feed along the migration route $(13,21-28)$. The extent

117 to which these feeding bouts occur is unclear.

118 Only one study investigating humpback whale migration has looked specifically at the

119 Southeastern Pacific DPS. Felix and Guzman (2014) compiled opportunistic sightings of

120 humpback whales from 1994 to 2012 along the coast of Chile and Peru from the SIBIMAP

121 database and deployed satellite tags on animals in waters off of Ecuador to track migration. The

122 SIBIMAP database showed evidence of a coastal migration route, which Felix and Guzman

123 suggested might be used by females with calves, while the satellite tags procured partial

124 migration tracks for 6 animals on their southbound migration. Unfortunately, the majority of the

125 tags ceased transmissions before departing Peru. While one animal was tracked relatively

126 consistently to halfway down Chile, complete migration tracks were not available for any

127 animals and partial migration tracks represented a very abbreviated portion of migration (21).

128 Based on their average speed estimates $\left(4.05 \mathrm{~km} \mathrm{~h}^{-1}\right)$ from these whales, Felix and Guzman

129 suggested that migration of single whales in the Southeastern Pacific DPS would last on average

$13066.4 \mathrm{~d}(\mathrm{SD}=13.25)$ if using the offshore route and $70.8 \mathrm{~d}(\mathrm{SD}=14.12)$ along the coastal route

131 (21).

\section{Migratory Species Concerns}

134 Generally, animals that exhibit long-distance migrations are vulnerable to climate change 
$135(1,29)$, and gaps in scientific knowledge on marine mammal migration have been cited as a

136 significant barrier to the conservation of cetacean populations $(1,29,30)$. Without complete

137 knowledge of the annual movements, including physical migratory routes and migratory

138 connectivity amongst populations or management units, conservation measures may be deployed

139 in wrong place, time, or for the wrong purpose (31). Indeed, addressing gaps in knowledge

140 regarding migrations from feeding to breeding regions as climate-driven changes in feeding

141 ground environments become more likely is crucial, as these changes can have significant effects

142 on the timing of arrival of individuals in breeding areas and therefore their reproductive success

143 (7,29). However, despite, or because of, having one of the longest migrations in the world, half

144 of the humpback whale migratory cycle has remained unexamined; not a single study has

145 investigated the behavior and route of whales during migration from foraging to breeding 146 grounds.

The primary goal of this research is to use satellite telemetry and state-space animal

148 movement models to explore gaps in our knowledge regarding the different parameters - speed,

149 migratory triggers, migratory duration, migratory timing, migratory foraging behavior, and

150 migratory sex and reproductive segregation- and geographic routes of the migratory pathways of

151 the humpback whale by providing a first look at the Southeastern DPS's migratory journey from

152 the Antarctic foraging ground to a tropical breeding ground.

\section{METHODS}

\section{Tag Deployment}

155 In 2012, 2013, 2015, 2016, 2017, and 2018, we deployed 62 satellite-linked transmitting

156 tags onto humpback whales in nearshore waters around the WAP from January to May. These 
157 animals were from the Southeastern Pacific DPS, which breeds off the Western coast of South 158 and Central America (3). Wildlife Computers (Redmond, WA, USA) SPOT5, SPOT 6, and 159 MARK 10 Platform Transmitting Terminals (PTTs) were utilized and tagging was limited to 160 adult-sized animals $(>12 \mathrm{~m})$. Each tag was contained in a sterilized housing and was anchored in

161 the tissue beneath the blubber near the dorsal with stainless steel barbs, with the transmitting 162 antenna remaining free outside of the animal (5). Tags were deployed from a range of 3-10 m 163 from a Zodiac Mark V or a Solas ridged-hulled inflatable boat using an ARTS Whale Tagging 164 PLT compressed air system (32).

Satellite transmissions were activated via a salt-water switch, and locations of the whales were obtained through the Argos System of polar-orbiting satellites (Argos, 1990). Tags were

167 programmed to transmit during specific hours and days. Since the tags were also being utilized

168 for other year specific projects, duty cycling varied across years. In 2012, tags were programmed

169 to transmit between 00:00-04:00 and 12:00-16:00 GMT. In 2013, tags were programmed to duty

170 cycle 3 hours on, 3 hours off, except for Sirtrack tags (identified by PTT IDs starting with 113),

171 which duty-cycled at 6 hours on/6 hours off. The 2015 tags were programmed to transmit

172 continuously, while in 2016 tags, some tags were programmed to transmit continuously, while

173 three were programmed to duty cycle at 1 day on, 4 days off. Tags deployed in 2017 were

174 programmed to duty cycle $12 \mathrm{hr}$ on, $12 \mathrm{hr}$ off.

\section{Demographic Information}

176 Skin and blubber biopsy samples were obtained from tagged whales whenever possible

177 using standardized remote biopsy techniques (33). Samples were obtained from the upper flank

178 below the dorsal fin (34). Blubber samples were used to provide life history and demographic

179 information as covariates in models assessing migratory behavior. To determine the sex of 
180 biopsied whales, genomic DNA was extracted from these samples using a proteinase K digestion

181 followed by a standard phenol-chloroform extraction method (35). To assign pregnancy within

182 sampled females, progesterone, a lipophilic steroid hormone, was quantified from a sub-sample

183 of blubber using a progesterone enzyme immunoassay (36). Pregnancy was then assigned by

184 comparing the measured progesterone concentrations across a pre-validated binary logistic

185 model developed from humpbacks of known pregnancy status sampled in the Gulf of Maine 186 (36).

188 Data Processing

$189 \mathrm{R}$ (version 3.4.3, R Core Team, 2017) was used to filter raw observations from the 190 satellite tags to remove points without location data, points with Argos error quality class Z 191 (invalid location), and points with duplicate timestamps. In addition, clearly implausible points 192 (e.g. on land or hundreds to thousands of kilometers from expected location) were visually 193 inspected and removed. Maps of the animals' tracks were plotted using ggmap (37) in R (R Core 194 Team, 2017).

Whales were determined to be migrating when they started a northward journey from the 196 WAP without any significant or lasting return movements. The date of departure for each whale 197 was determined visually by graphing latitude as a function of Julian day and assessing at which 198 point the animal moved northward without any return movements. The static nature of the 199 environmental data combined with the mobile nature of the humpback data's mobile nature 200 precluded us from statistically evaluating the potential environmental trigger of light. Instead, we 201 matched daylight hours in the WAP to tagging data and graphed this against the animals' 202 latitudes in the same fashion that we determined departure dates. 
To determine rates of migration, speeds on the migratory route were calculated with data

204 corrected for location error with the simple default Hierarchical State Space Movement Model

205 with a 12-hour timestep fitted in R using BSAM (Jonsen 2016, R Core Team 2017). Rate was the

206 distance of the linear vector between 12-hour timestep locations. Distances between locations

207 were calculated using the function distanceTrack from the Argosfilter package (Freitas 2012, R

208 Core Team 2017). Average rates were calculated as the average of all 12-hour timestep rates for

209 each animal.

As coastal nations have exclusive sovereign rights for the purpose of conserving and

211 managing marine species within the bounds of their jurisdiction (38), the amount of time the

212 migrators spent within EEZ boundaries was calculated by summing the number of regular

213 timestep observations from the BSAM model within each country's national waters. While the

214 satellite tags themselves did not collect data with great regularity, the BSAM model calculates

215 true unobserved locations along regular time intervals from available data, and these intervals

216 were utilized for EEZ analysis.

There were a number of locations where the tracks converged and allowed for a logical

218 division of the migration corridor into three spatial sections, "WAP-Cape Horn (Drake passage),"

219 “Cape Horn (Chile) - Peninsula de Paracas (Peru)," and "Peninsula de Paracas (Peru)- Zona

220 Reserverda Illescas (Peru)." Since not all tags transmitted for the entire migratory journey, these

2213 discrete spatial sections allowed for a more valid estimation and comparison of speeds in some

222 sections along the journey. Average migratory speed was calculated for each section, as well as

223 for the breeding area. As humpback whales leave the Antarctic peninsula at different times, a

224 simple linear regression was performed using Julian day (predictor variable) and speed (response

225 variable) to investigate whether the timing of migration affected the speed at which the animal 
226 migrates. Because very few tags transmitted to completion of migration, we chose to look at

227 speed in the first migratory section from the WAP to Cape Horn (latitude $=-55.9833$ ). All data

228 above -55.9833 , as well as all animals that did not reach -55.9833 , were filtered out, and the

229 average speed over the section was calculated for each remaining individual. To correct for

230 issues of heteroskedasticity, speed was transformed with a log function, and the residual plot was

231 assessed for any obvious signs of nonlinearity and heteroskedasticity. A QQ plot was used to

232 check for the normality of residuals, and the data were tested for influential data points. To

233 determine whether sex and reproductive status had an impact on speed, two Welch's ANOVA

234 tests were performed on the same speed data, using sex (male/female) as the predictor variable in

235 the first test, and sex/reproductive status as the predictor variable in the second test (male,

236 female-pregnant, female-not pregnant). For all tests, P-values $<.01$ indicated strong support, p-

237 values between .01 and .1 offered suggestive, but inconclusive support, and p-values $>.1$

238 indicated no support $(39,40)$.

239 Discrete behavioral modes were determined by manually constructed hierarchical

240 Bayesian state-space movement models. This was a departure from the simpler models use to

241 assess true locations, as it allowed for differences in movement norms associated with behavioral

242 states depending on whether the animals were in the foraging grounds, breeding grounds, or

243 migratory route. This model associated spatial patterns of animal movement with predicted

244 behavioral states while simultaneously accounting for and correcting the significant error

245 inherent in Argos Satellite location data.

246 We used a discrete-time dynamic correlated random walk model following Jonsen et al.

247 (2005) and Bestley et al. (2013), where each movement stemmed from either a 'traveling or

248 'area-restricted search' (ARS) state $(41,42)$. When humpback whales encounter sufficient prey 
249 areas, they often engage in ARS by decreasing their travel speeds and increasing their turning

250 angle radius and frequency; consequently ARS behavior is defined as shorter step lengths with

251 larger and more variable turning angles. The terminology ARS is used instead of foraging, as

252 whales may also be engaging in other behaviors such as resting and breeding in this state and our

253 measurements are not based off of a direct measure of feeding but rather use movement metrics.

254 In humpback whales this spatial signature may persist for up to several days in one location (43).

255 The traveling state, which is thought to occur when the animals are either actively migrating or

256 located in habitats unsuitable for foraging, is characterized by fast travel rates and infrequent and

257 small turning angles; in a state-space model this behavior is recognized by the presence of long

258 step lengths with small and infrequent turning angle radius.

259 The first component of the state space model was the process model, which estimates

260 animal behavior with a first-difference correlated random walk (42). The process model took the

261 form:

$$
\mathrm{d}_{\mathrm{t}} \sim \mathrm{N}_{2}\left[\gamma_{\mathrm{bt}} \mathrm{T}\left(\theta_{\mathrm{bt}}\right) \mathrm{d}_{\mathrm{t}-1}, \Sigma\right]
$$

263 where $d_{t}$ is the difference between true unobserved locations and coordinate vectors $\mathrm{x}_{\mathrm{t}}$ and $\mathrm{xt}_{-1}$

264 and $\mathrm{N}_{2}$ is a bivariate normal distribution with covariance matrix $\Sigma$, where $\sigma_{l o n}^{2}$ is the process

265 variance in longitude, $\sigma_{\text {lat }}^{2}$ is the process variance in latitude, and $\rho$ is the correlation coefficient.

$266 \gamma$ is the autocorrelation of direction and speed between consecutive locations, with a value of

267 between 0 and 1 ( $\gamma=0$ would signal a simple random walk). $b_{t}$ is an index used to denote

268 behavioral mode, e.g. ARS or traveling. $\mathrm{T}(\theta)$ is the transition matrix with mean turning angle $\theta$

269 which provides the rotation required to move between $\mathrm{d}_{\mathrm{t}}$ and $\mathrm{d}_{\mathrm{t}-1}$.

270

$$
T(\theta)=\left(\begin{array}{cc}
\cos \theta & -\sin \theta \\
\sin \theta & \cos \theta
\end{array}\right)
$$




$$
\Sigma=\left(\begin{array}{cc}
\sigma_{\text {lon }}^{2} & \rho \sigma_{\text {lon }} \sigma_{\text {lat }} \\
\rho \sigma_{\text {lat }} \sigma_{\text {lon }} & \sigma_{\text {lat }}^{2}
\end{array}\right)
$$

This model is considered a switching model in the vein of Jonsen, 2005, and a separate

273 process model was run for each of the two behavioral states. As we are including two behavioral

274 states, there were four possible transitions, two of which are calculated: $\alpha_{1}$, the probability of

275 remaining traveling at time $t$ if traveling at time $t-1$, and $\alpha_{2}$, the probability of traveling at time $t$

276 given foraging at time $\mathrm{t}-1$.

The second component of the state space model was the measurement equation or observation model. This equation calculated the temporally regular unobservable "true" locations

279 of the animals needed for the process equation from the error-prone and temporally irregular

280 Argos location observations:

$$
\mathrm{y}_{\mathrm{t}, \mathrm{i}}=\left(1-\mathrm{j}_{\mathrm{i}}\right) \mathrm{x}_{\mathrm{t}-1}+\mathrm{j}_{\mathrm{i}} \mathrm{x}_{\mathrm{t}}+\varepsilon_{\mathrm{t}}
$$

where $\mathrm{i}$ is an index for locations between times $\mathrm{t}$ and $\mathrm{t}+1$, and $\mathrm{j}_{\mathrm{i}}$ represents the proportion

283 of the timestep at which the $\mathrm{i}^{\text {th }}$ observation is made. $\mathrm{X}_{\mathrm{t}}$ is the unobserved true location of the

284 animal at time $\mathrm{t}, \mathrm{y}_{\mathrm{t}, \mathrm{i}}$ is the $\mathrm{i}^{\text {th }}$ observed position during the regular time interval $\mathrm{t}-1$ to $\mathrm{t}$, and $\varepsilon_{\mathrm{t}}$ is a

285 random variable representing the error in the Argos locations. The variance in Argos

286 observations was fixed for each Argos class error as demonstrated in Jonsen et al. 2005. Various

287 classes of Argos errors are strongly non-gaussian, and are thus traditionally calculated with $\mathrm{t}$

288 distributions (42). However, this can make the model so computationally complex that it cannot

289 converge. This occurred with our models, and to counter this we removed any extreme and

290 implausible locations from our data using the Argosfilter package in R (Freitas 2012, R Core

291 Team 2017), and then ran the observation model with a multivariate normal distribution as done

292 in Weinstein et al. $(2017 \mathrm{a}, 2017 \mathrm{~b})(4,5)$. We used a timestep of 12 hours, which we deemed to be 
293 a conservative balance between taking into account gaps in the data as well as ensuring

294 behaviors did not change between locations. Although only two behavioral states were modelled,

295 the means of the MCMC samples provided continuous values from 1-2. A mean behavioral

296 mode of $<1.25$ was considered traveling, whereas a value $>1.75$ represented Area-Restricted

297 Search. Estimations between 1.25 and 1.75 were treated as uncertain (44).

To help address the inconsistent transmitting nature and duty cycling of the tags as much

299 as possible, a joint estimation, in which estimation of behavioral states is conducted jointly

300 across multiple animal movement datasets rather than individuals, was done. This method

301 assumes that movement parameters may differ among individuals but are drawn from the same

302 set of distributions, and allows the model to estimate parameters and state variables with greater

303 precision by assuming a general range in value for all animals to borrow strength across multiple

304 datasets, thus filling in for any animals with suboptimal data (45).

Priors for $\gamma$ and $\theta$ were set to reflect the assumptions that the travelling state would have

306 greater autocorrelation and lower mean turning angles than the ARS state. To allow for variance

307 in transition probability and behavioral state characteristics as the animals switched from

308 feeding, to migratory, and then breeding areas, the variable Month was set as a random variable,

309 allowing parameters for transition probability and autocorrelation to come from different

310 probability distributions each month. This is different than a traditional BSAM model and

311 important as it allowed for potential differences in spatial characteristics of behaviors - ARS in

312 foraging and breeding grounds may present differently than ARS on the migratory route. This

313 model was fitted in R using the software JAGS (Plummer, 2013) and the R rjags package

314 (Plummer, 2016; R Core Team 2017). Where a gap of $>1$ day existed in the raw satellite

315 transmission data the individual track was split and run as separate segments to avoid 
316 interpolating over long periods. Each model was run with two MCMC chains, consisting of

317270,000 iterations each, the first 250,000 discarded as burn-in. The remaining 20,000 iterations

318 were thinned, retaining every $8^{\text {th }}$ sample to reduce autocorrelation and computational burden.

319 The goodness of fit and chain convergence were assessed using the Gelman-Rubin statistic, and 320 parameters with Gelman- Rubin ( $\mathrm{R}$ ) of less than 1.1 were considered converged as outlined by

321 Gelman and Hill (2006) (46). Runs were conducted on the UCSC Hummingbird computational

322 cluster with chains running in parallel.

\section{RESULTS}

324 Tag Deployment

325 Between 2012 and 2018, 16 of the 62 animals tagged in the WAP commenced migration, 326 transmitting a total of 35,642 locations, with 5 tags transmitting locations to the breeding 327 grounds. The transmission time of these tags ranged between 42 and 266 days (mean=108 d, $328 \mathrm{sd}=63.7$ ). Start dates varied greatly, with departure dates ranging from $3 / 16$ to $7 / 15$ (Table 1).

329 Animals with tags that continued to transmit to the completion of migration reached the breeding 330 grounds (designated as Zona Reserverda Illescas, Peru), as early as June 19th, and as late as 331 August $8^{\text {th }}$ (Table 1).

[INSERT TABLE 1] 
Of the 16 animals that initiated migration, four were pregnant females, four were resting

337 females (one juvenile), four were males, and four did not have biopsy samples and were thus of

338 unknown sex. None of the animals were accompanied by calves at the time of tagging.

Individual data analyses

The start of migration, end of migration tracked, duration of migration tracked, number of

342 transmissions during migration, and length of migration tracked were found for each animal

343 (Table 1). The animals showed differences in regards to their migratory speeds, the start of

344 migration, and geographic routes. A summary of each of the 16 animals' individual movements

345 is provided in Table 1, and their routes can be seen in Figures $1 \& 2$.

347 Migratory Route findings and patterns

348 Of the 16 migrators, five (PTT ID=112699, 121210, 123232, 131130, and 166123) made

349 it all the way to the breeding grounds, representing the first complete migratory tracks of animals

350 in the Southeastern Pacific DPS. The animals all used routes with coastal and open water

351 segments to migrate up the Western side of South America (Figures 1-2). One animal had a

352 particularly unusual trajectory - the tag on 123232 ceased transmissions entirely during a large

353 part of the northward migration, but then resumed and recorded the entire southward migration

354 until October. By that time, the whale had returned to the Antarctic foraging grounds. This

355 represents the first satellite tagging of an animal on both legs of migration. Multiple whales (PTT

356 IDs $=131130,123232,121210$, and 166123) crossed the equator and one ventured as far as 8.94

357 degrees north $(\mathrm{PTT}=131130)$. Interestingly, no clear stratification of route choice by sex or

358 reproductive status was found (Figure 1C). 
Whales left from numerous locations on the peninsula and remained relatively dispersed

360 in the Drake Passage (Figures 1 and 2). Many of the animals then passed close to South

361 America's western tip, resulting in a bottleneck that lasted from the tip of the continent until

362 approximately $-47^{\circ}$ in the region of Chile's Parque Nacional Laguna San Rafael. The whales'

363 trajectories then spread out again and ventured into deeper waters until hitting the coast near

364 Peru's Peninsula de Paracas, at which point they migrated through a narrow corridor near the

365 coast and up through the breeding area. Four whales, (PTT=131136 -2016, sex unknown;

366 PTT=166126 - 2017, juvenile resting female; PTT=166125 - 2017, pregnant female; PTT=

367166122 - 2017, pregnant female), diverged from these trends, choosing deep water routes in

368 areas where the rest of the whales stayed in coastal areas.

The average amount of time spent in national waters for the 5 animals with complete

370 migration tracks (PTT ID $=112699,121210,123232,131130$, and 166123$)$ was $72 \%$ of total

371 migration time (Table 2).

372 The average speed for all the animals was $5.88 \mathrm{~km} \mathrm{hr}^{-1}(\mathrm{SD}=1.31)$. In general, average

373 speeds followed a slow-fast-slow trajectory by track segment, with the average speed calculated

374 for the animals highest during the middle section of migration from Cape Horn to Peninsula de

375 Paracas, and lowest in the breeding area (Table 1, Figure 3). 15 migrators had tracks reaching to

376 Cape Horn, and their average speeds over the distance can be seen in Table 1. The regression

377 results showed suggestive but inconclusive support for the hypothesis that whales have faster

378 migratory speeds the later they leave the peninsula $(F(1,13)=4.117, p=.06346)$. There was no

379 relationship between speed and $\operatorname{sex}(\mathrm{F}(2,3.11=0.003, \mathrm{p}=.96))$ or speed and sex / reproductive

380 status $(\mathrm{F}(2,4.8=.37, \mathrm{p}=.71))$. 
Table 2: Percentage of migratory time in national waters off the coast of South America by satellite tagged humpback whales. Only the 5 whales with complete migration tracks as

384 generated by BSAM were included.

\begin{tabular}{cccccc}
\hline $\begin{array}{c}\text { Animal } \\
\text { ID }\end{array}$ & Chile (\%) & Peru (\%) & Ecuador (\%) & $\begin{array}{c}\text { Total Migratory } \\
\text { Route in National } \\
\text { Waters (\%) }\end{array}$ & $\begin{array}{c}\text { Migratory Route } \\
\text { in International } \\
\text { Waters (\%) }\end{array}$ \\
\hline 112699 & $48 \%$ & $28 \%$ & $3 \%$ & $79 \%$ & $21 \%$ \\
121210 & $39 \%$ & $21 \%$ & $4 \%$ & $64 \%$ & $36 \%$ \\
123232 & $39 \%$ & $25 \%$ & $6 \%$ & $70 \%$ & $30 \%$ \\
131130 & $53 \%$ & $17 \%$ & $3 \%$ & $73 \%$ & $27 \%$ \\
166123 & $39 \%$ & $30 \%$ & $7 \%$ & $75 \%$ & $25 \%$
\end{tabular}

The animals appeared to be almost exclusively traveling during their northward

387 migration. Of the 4,230 behavioral points utilized by the model on the Northbound migratory

388 route before Zona Reserverda Illescas, 3,875 were classified as Traveling, 294 as Unknown, and

$38961(1 \%)$ as ARS. The 61 ARS locations all belonged to animal 123236 and occurred from March

$39023-26$ around $-66^{\circ} \mathrm{W},-60^{\circ} \mathrm{S}$ in the Drake Passage. An additional 332 instances of ARS were

391 observed in animal 123232 in the Drake passage on its southward return migration. From the

392 movement patterns, it appears the animal may have already started its foraging season at this

393 point but was kept further away from the peninsula as a result of sea ice extent (Figure 4).

394 Unfortunately, not all the data were usable. The model required at least one transmission per 395 timestep during three consecutive timesteps to create a track. This, combined with the varied 396 nature of the duty cycling across the years as well as the inconsistent transmitting nature of the 397 tags, resulted in a portion of the data being lost. 
The results of our tracking analyses provide the first continuous description of humpback

401 whale migratory behavior from a feeding to a breeding ground as well as the first complete

402 migratory tracks of the Southeastern Pacific DPS. These humpback whales exhibited staggered

403 departures from many locations along the WAP and embarked on northward migrations lasting

404 between 41 and 54 days. The tagged individuals migrated at varying speeds, and a positive

405 suggestive but inconclusive relationship between date of departure and speed indicates that

406 animals leaving later may travel at faster speeds, potentially to make up for their later departure

407 dates. Except for one animal in the Drake passage, ARS, which can be a proxy for foraging, did

408 not occur on the northbound migratory route.

The telemetry data identified two previously undocumented geographic bottlenecks: the

410 consolidation of the tracks starting at the coast of the Southern tip of Chile and stretching until

411 the Parque Nacional Laguna San Rafael, as well as the portion of the annual cycle spanning the

412 coastal areas from Peru's Peninsula de Paracas to the border between Columbia and Ecuador and

413 into Panama (Figure 1B). Interestingly, the first bottleneck region lines up approximately with

414 the Straits of Magellan and Northern Chilean Patagonia, two areas that have been suggested as

415 alternative foraging grounds for animals in the Southeastern DPS; however, no instances of ARS

416 were documented in these areas, nor did animals deviate from their northbound migration to

417 enter the Straits of Magellan $(47,48)$. It is worth noting that one individual recorded "Unknown"

418 behavior near Northern Chilean Patagonia.

Our migratory tracks tentatively identify the area around Zona Reservada Illescas, Peru,

420 as the start of the breeding area based on abrupt route change and the transition from transiting to

421 ARS in animal PTT=123224. This delineation of the breeding ground is more in agreement with

422 Guzman (21) than Rasmussen (2), which placed the border close to the equator in Salinas, 
423 Ecuador, more than $550 \mathrm{~km}$ away. Tagged whales in our study reached as far north as Panama,

424 which was in agreement with Rasmussen's findings regarding the geographical extent of the 425 breeding grounds.

One tagged whale, PTT 123232, provided information on the complete migratory cycle

427 from the Antarctic to the tropical breeding ground and back to the Antarctic. While the tag

428 stopped transmitting for a significant portion of the northward migration, this deployment

429 represents the first tagged humpback to provide data for a continuous annual cycle. The

430 southward route lined up closely with the northward route, indicating that humpbacks may use

431 the same routes, regardless of migratory direction.

433 characteristics of migration - segregation along sex, reproductive, and age classes. While our

434 sample size was not large $(\mathrm{n}=16)$, it was much larger than most similar cetacean telemetry

435 studies of migration, and the lack of stratification is notable. It may be possible that segregation

436 by sex and reproductive status has been overemphasized in past literature, that this pattern varies

437 by DPS and is not adhered to in the Southeastern Pacific DPS, or that there are additional

438 parameters that have not been accounted for. Our sample's nature can also explain some of the

439 discrepancies - Felix and Guzman (2014) looked only at southbound migration and hypothesized

440 that the coastal route vs oceanic route differed by whether the animal was a single adult or

441 mother with calf. By the time of the northbound migration, calves had already been weaned and

442 none of our tagged females were accompanied by offspring; therefore, the lack of observed

443 coastal route does not contradict their findings.

444 It is also of note that our findings seemingly oppose those of Avila et al (2020), which 
445 states that whale arrival in the breeding grounds is becoming consistently earlier, with an average

446 arrival date of the last week of May (10). Of our 16 animals, 8 had not even commenced

447 migration by the last week of May, let alone made it to the breeding grounds.

$448 \quad$ Our study supported Dawbin's (1966) conclusions on migratory foraging, which stated

449 that the animals did not forage on their northward migration. While telemetry data cannot

450 conclusively rule out foraging behavior, only $1 \%$ of our recorded locations on the migratory

451 route indicated ARS and all of these points belonged to one animal and occurred in the Drake

452 Passage. Without more detailed data (e.g. dive parameters) it would not be possible to determine

453 if this ARS included actual feeding behavior versus the myriad other reasons that an animal may

454 cease transiting for a short period of time. A few cases of behavior were classified as unknown

455 on the route, but the majority of points in this category were found in the breeding or foraging

456 areas. As previously stated, certain instances of feeding bouts have been recognized on the

457 migratory route in recent years $(13,21,23,25,27,49)$. However, all of these recorded instances

458 have occurred while individuals were migrating from breeding to feeding grounds. It is possible

459 that supplementary feeding is a phenomenon relegated only to the route from breeding to feeding

460 grounds - perhaps because there is less of a definitive date that whales need to reach their

461 destination by, or because energy stores are running low while on the journey from foraging to

462 breeding grounds whales have just replenished their food stores.

The average migratory rate for our animals was $5.88 \mathrm{~km} \cdot \mathrm{h}^{-1} \pm 1.31$ and $5.88 \mathrm{~km} \cdot \mathrm{h}^{-1} \pm .59$

464 for the complete tracks of the 5 animals that completed migration. Our animals completed the 465 migration in $41-54$ days and traveled between $33^{\circ}-43^{\circ}$ per month. These speeds were 466 significantly faster than Dawbin (1966), who recorded south to north speeds of $15^{\circ}$ per month, 467 with approximate migration durations of 60-120 days. They were slightly higher than previously 
468 recorded telemetry speeds of $4.04 \pm 1.08 \mathrm{~km} \cdot \mathrm{h}^{-1}(21), 4.3 \pm 1.2 \mathrm{~km} \cdot \mathrm{h}^{-1}(13), 4.5 \mathrm{~km} \cdot \mathrm{h}^{-1}(14)$, and

4693.83 and $3.48 \mathrm{~km} \cdot \mathrm{h}^{-1}(15,16)$. It is possible that the whales in our study utilized coastal currents,

470 such as the Humboldt Current, along the west coast of South America, to increase their traveling

471 speeds without incurring additional energetic costs. It is also possible that the Southeastern

472 Pacific DPS experiences slightly higher migratory speeds than other populations or that,

473 alternatively, migratory rates in the direction of the breeding ground are higher than that of the

474 return route given that the whales are at their maximum energy storage and are motivated to

475 establish themselves on breeding grounds.

476 The telemetry data also revealed that our humpback whale speeds, on average, were not 477 constant and tended to be highest in the middle of migration. If this is a typical pattern, it could

478 mean that many of the telemetry estimations in different studies of average migratory rates could 479 be biased if calculations are based on only a short portion of the route.

We found no evidence that migration was triggered by daylight hours. There was no 481 number of daylight hours at which all whales initiated migration. Instead, the whales departed 482 from the Antarctic in conditions ranging from two to eight hours of sunlight. Suggestive support 483 was offered for a positive relationship between migratory speed and departure date. This increase 484 of speed with a later departure date could indicate that animals feel compelled to make up for 485 lost time, presumably to arrive at the breeding ground in a coordinated manner.

\section{Limitations}

488 Due to the difficulty tagging marine animals, the sample size will always be an issue in 489 marine mammal studies, and this should be kept in mind when viewing our results. In addition, 
490 while satellite telemetry makes it possible for us to obtain hitherto unheard-of levels of detail in 491 our data, it is a relatively new technology, and limitations can present themselves. Many of our

492 tags demonstrated variability in transmission performance. Failure to transmit may be caused by 493 mechanical or electronic failure, poor implantation, or suboptimal position of tag deployment. A 494 combination of variability in transmission performance and differences in duty cycling regimes

495 across years meant that much of the data could not be incorporated into the HSSMs, and the lack 496 of ARS may reflect data limitations stemming from a loss of transmission points. Future studies

497 should be made to pick a duty cycling regime implemented consistently across years and

498 specifically with state-space model timesteps in mind. In addition, the JAGS model should

499 include the ability to fill in smaller gaps, as seen in BSAM and Jonsen (2007) (44).

501 Management Implications

502 The conservation of migratory species requires a knowledge of migratory routes'

503 geographical locations, which can highlight areas of particular importance to a species $(29,31)$.

504 The humpback whales in this study spent the vast majority of their migratory time in territorial or 505 exclusive economic zone waters of several nations, and knowledge of the jurisdictions in which 506 the animals migrate can be taken into account when determining management policies as coastal 507 nations have exclusive sovereign rights for conserving and managing marine species within the 508 bounds of their jurisdiction (38). To maximize conservation resources, the concept of site conservation, specifically

510 focusing resources on sites particularly important to a species' life history, has been developed

511 (50). Bottleneck sites, as well as breeding areas, are considered key areas (50). This study

512 identifies two bottleneck regions off Chile's coast and from Peru's Peninsula de Paracas up into 
513 Panama (Figure 1B). These two areas represent regions to concentrate conservation resources

514 and pass legislation, and this information can be shared with the appropriate national

515 organizations to advance efficient and effective conservation measures such as Marine Mammal

516 Protected Areas (MMPA) (51). In addition, our data has been contributed to the Migratory

517 Connectivity in the Ocean project (MiCO), which is currently developing a system to aggregates

518 and generated actionable knowledge to support worldwide conservation efforts for numerous

519 migratory species (52).

\section{CONCLUSION}

Understanding humpback whale migratory behavior and routes gives us a greater context

524 to make effective and efficient conservation decisions in the face of the animals' changing

525 environment. This study is a starting point for the long-term monitoring of the animals in an era

526 of climate change. In the coming years, a significant challenge in the conservation of migratory

527 species will be migrants' potential to shift routes in response to their changing environment.

528 Long-term monitoring programs will allow conservationists and management specialists to

529 monitor and anticipate these changing behaviors (29), identify conservation priorities, and

530 provide baseline data against which the impacts of climate change on ecosystems and migratory

531 species can be highlighted $(19,29)$. Future studies should continue to grow the sample size and

532 investigate routes, behaviors, sex, and reproductive segregation of migration. In particular,

533 emphasis should be given to the bottleneck region between Magellan and Northern Patagonia's

534 strait, to research whether or not our animals are feeding in this location on Antarctica's return 
535 route. The information presented here currently defines the behavior of humpback whale

536 migratory behavior from feeding to breeding grounds and can serve as a baseline for future work

537 on the species to compare and contrast how different environmental conditions and populations

538 impact this behavior. 
558 ARS: Area-Restricted Search

559 EEZ: Exclusive Economic Zone

560 LTER: Long Term Ecological Research Project

561 WAP: Western Antarctic Peninsula

562 MiCO: Migratory Connectivity in the Ocean project

563 MMPA: Marine Mammal Protected Area

564 UAS: Unmanned Aerial System

566 Ethics approval and consent to participate

567 All animals were handled by experienced professionals under permits: NMFS 14907, 14,809, and

568 14,856, ACA Permits 2009-013 and 2015-011, Duke University IACUC A049-122-01, Ucsc Iacuc

569 friea1706, and OSU ACU 4513

571 Consent for publication

572 Not applicable

573

574 Availability of data and materials

575 The humpback whale datasets generated and or analysed during the current study are available in the

576 WhalePhys repository, https://github.com/bw4sz/WhalePhys/tree/master/Data/Humpback

577 The Palmer Station datasets analyzed during the current study are available in the Palmer Station

578 Weather - Daily Averages repository,

579 https://oceaninformatics.ucsd.edu/datazoo/catalogs/pallter/datasets/28 


\section{Competing interests}

583 The authors declare that they have no competing interests

\section{$585 \quad$ Funding}

586 Research was supported by Antarctic Wildlife Research Fund, NSF OPP National Science

587 Foundation ANT- 0823101, 1250208, and 1440435, the International Whaling Commission, the

588 Southern Ocean Research Partnership, and the Hogwarts Running Club.

590 Authors' contributions

591 ASF, LI, RTM and LP collected the data. LP led laboratory/tissue analysis. ASF and MM conceived 592 the analysis. MM performed the analysis and wrote the text. WG provided energetics support. All 593 authors commented on text and figures. All authors read and approved the final manuscript.

\section{Acknowledgements}

596 We are grateful to the Australian Antarctic Division for their support of this research, with special 597 thanks to Ben Weinstein for all of his quantitative support, the NSF LTER, Kelvin Rushworth, Mike 598 Double, Robert Pitman, John Durban, Matthew Bowers, Erin Pickett, and Zachary Swaim. 
2. Marine Mammal Institute and Department of Fisheries and Wildlife, Hatfield Marine Science Center, Oregon State University, Newport, OR, USA

3. Australian Marine Mammal Centre, Australian Antarctic Division, Kingston, Tasmania, Australia

4. Department of Biology, Hopkins Marine Station, Stanford University, Monterey, CA,

608 USA

5. Duke University Marine Laboratory, Duke University, Beaufort, North Carolina, USA

610

6. Chicago Zoological Society's Sarasota Dolphin Research Program, Sarasota, FL, USA

611

612

613

614

615

616

617

618

619

620

621

622

623

624

625

626 


\section{References}

631

632 1. Learmonth JA, Macleod CD, Santos MB, Pierce GJ, Crick HQP, Robinson RA. Potential 633 Effects of Climate Change on Marine Mammals. An Annu Rev. 2006;44:431-64.

634 2. Rasmussen K, Palacios DM, Calambokidis J, Saborío MT, Dalla Rosa L, Secchi ER, et al. 635 Southern Hemisphere humpback whales wintering off Central America: insights from water 636 temperature into the longest mammalian migration. Biol Lett [Internet]. 2007 Jun 22 [cited 6372017 Nov 13];3(3):302-5. Available from: http://www.ncbi.nlm.nih.gov/pubmed/17412669

638 3. NOAA. Endangered and Threatened Species; Identification of 14 Distinct Population 639 Segments of the Humpback Whale (Megaptera novaeangliae) and Revision of Species-Wide 640 Listing [Internet]. 2016 [cited 2019 Oct 29]. Available from:

$641 \quad$ www.fisheries.noaa.gov/pr/species/

642 4. Weinstein BG, Double M, Gales N, Johnston DW, Friedlaender AS. Identifying overlap 643 between humpback whale foraging grounds and the Antarctic krill fishery. Biol Conserv 644 [Internet]. 2017 Jun [cited 2017 Nov 16];210:184-91. Available from:

645 http://linkinghub.elsevier.com/retrieve/pii/S000632071730023X

646 5. Weinstein BG, Friedlaender AS. Dynamic foraging of a top predator in a seasonal polar 647 marine environment. Oecologia [Internet]. 2017 Nov 15 [cited 2018 Apr 12];185(3):427-35.

648 Available from: http://link.springer.com/10.1007/s00442-017-3949-6

649 6. Ducklow H, Fraser W, Meredith M, Stammerjohn S, Doney S, Martinson D, et al. West 650 Antarctic Peninsula: An Ice-Dependent Coastal Marine Ecosystem in Transition. 
Oceanography [Internet]. 2013 Sep 1 [cited 2018 Oct 17];26(3):190-203. Available from: https://tos.org/oceanography/article/west-antarctic-peninsula-an-ice-dependent-coastal-

653 marine-ecosystemintransit

$6547 . \quad$ Norris K, Dawbin W. Whales, dolphins, and porpoises. Univ. of California Press; 1966. 789 $655 \quad \mathrm{p}$.

656 8. Acevedo J, Rasmussen K, Félix F, Castro C, Llano M, Secchi E, et al. MIGRATORY DESTINATIONS OF HUMPBACK WHALES FROM THE MAGELLAN STRAIT FEEDING GROUND, SOUTHEAST PACIFIC. Mar Mammal Sci [Internet]. 2007 Apr 1 [cited 2018 Apr 28];23(2):453-63. Available from: http://doi.wiley.com/10.1111/j.17487692.2007.00116.x

661 9. Florez-Gonzalez L, Juan CA, Haase B, Bravo GA, Felix F, Gerrodette T. CHANGES IN WINTER DESTINATIONS AND THE NORTHERNMOST RECORD OF SOUTHEASTERN PACIFIC HUMPBACK WHALES. Mar Mammal Sci [Internet]. 1998

664 Jan 1 [cited 2018 Apr 28];14(1):189-96. Available from: http://doi.wiley.com/10.1111/j.1748-7692.1998.tb00707.x

666 10. Isabel Cristina Avila, Carsten F Dormann, Carolina Garcia, Luis Fernando Payan, Maria 667 Ximena Zorilla. Humpback whales extend their stay in a breeding ground in the Tropical Eastern Pacific. ICES J Mar Sci [Internet]. 2020 Feb 1 [cited 2020 Jul 17];77(1):109-18. Available from: https://academic.oup.com/icesjms/article-abstract/73/3/849/2458912

670 11. Félix F, Castro C, Laake JL, Haase B, Scheidat M. Abundance and survival estimates of the southeastern Pacific humpback whale stock from 1991-2006 photo-identification surveys in Ecuador. Vol. 3, J. CETACEAN RES. MANAGE. (SPECIAL ISSUE). 2011.

673 12. Bengtson Nash SM, Waugh CA, Schlabach M. Metabolic Concentration of Lipid Soluble 
Through Migration and Fasting. Environ Sci Technol [Internet]. 2013 Aug 20 [cited 2018 Apr 29];47(16):9404-13. Available from: http://pubs.acs.org/doi/10.1021/es401441n

677 13. Kennedy AS, Zerbini AN, Vásquez O V, Gandilhon N, Clapham PJ, Adam O. Local and migratory movements of humpback whales (Megaptera novaeangliae) satellite-tracked in the

14. Mate BR, Gisiner R, Mobley J. Local and migratory movements of Hawaiian humpback whales tracked by satellite telemetry. Can J Zool [nternet]. 1998 [cited 2020 Jul 4];76(5):8638. Available from: http://www.nrc.ca/cgi-bin/cisti/journals/rp/rp2_abst_e?cjz_z98008_76_ns_nf_cjz76-98

15. Zerbini A, Andriolo A, Heide-Jørgensen M, Pizzorno J, Maia Y, VanBlaricom G, et al. Satellite-monitored movements of humpback whales Megaptera novaeangliae in the Southwest Atlantic Ocean. Mar Ecol Prog Ser [Internet]. 2006 May 11 [cited 2017 Nov 16];313:295-304. Available from: http://www.int-res.com/abstracts/meps/v313/p295-304/

16. Zerbini A. Migration and summer destinations of humpback whales (Megaptera novaeangliae) in the western South Atlantic Ocean. J Cetacean Res Manag Spec [Internet]. 2011 [cited 2020 Jul 4]; Available from: https://www.academia.edu/11783203/Migration_and_summer_destinations_of_humpback_

694 17. Brown MR, Corkeron PJ, Hale PT, Schultz KW, Bryden MM. Evidence for a sex-segregated 695 migration in the humpback whale (Megaptera novaeangliae). Proceedings Biol Sci [nternet]. 1995 Feb 22 [cited 2017 Nov 16];259(1355):229-34. Available from:

698 18. Chittleborough R. Dynamics of two populations of the humpback whale, Megaptera 
novaeangliae (Borowski). Mar Freshw Res [Internet]. 1965 [cited 2017 Nov 16];16(1):33.

$700 \quad$ Available from: http://www.publish.csiro.au/?paper=MF9650033

701 19. Dawbin WH. Temporal segregation of humpback whales during migration in southern 702 hemisphere waters. Oceanogr Lit Rev. 1997;125-6.

703 20. Gabriele C, Craig A, Pack A, Herman L. Migratory Timing of Humpback Whales (Megaptera novaeangliae) in the Central North Pacific Varies with Age, Sex and Reproductive Status. Behaviour [Internet]. 2003 Aug 15 [cited 2017 Nov 30];140(8):981-1001. Available from: http://booksandjournals.brillonline.com/content/10.1163/156853903322589605

21. Félix F, Guzmán HM. Satellite tracking and sighting data analyses of Southeast Pacific humpback whales (Megaptera novaeangliae): Is the migratory route coastal or oceanic? Aquat Mamm [Internet]. 2014 [cited 2017 Dec 2];40(4):329-40. Available from: https://www.researchgate.net/profile/Fernando_Felix2/publication/281286471_Satellite_Tr acking_and_Sighting_Data_Analyses_of_Southeast_Pacific_Humpback_Whales_Megaptera_ novaeangliae_Is_the_Migratory_Route_Coastal_or_Oceanic/links/55df7f5c08aede0b572b8f

714 22. McLaughlin RJ. Bio-logging as marine scientific research under the law of the sea: A 715 commentary responding to James Kraska, Guillermo Ortuño Crespo, David W. Johnston, 716 bio-logging of marine migratory species in the law of the sea, marine policy 51 (2015) 394717 400. Mar Policy. 2015 Oct 1;60:178-81.

718 23. Best PB, Sekiguchi K, Findlay KP. A suspended migration of humpback whales Megaptera 719 novaeangliae on the west coast of South Africa [Internet]. Vol. 118, Marine Ecology Progress 720 Series. Inter-Research Science Center; 1995 [cited 2017 Nov 30]. p. 1-12. Available from: 721 http://www.jstor.org/stable/24849759

722 24. De Sá Alves LCP, Andriolo A, Zerbini AN, Pizzorno JLA, Clapham PJ. Record of feeding by 
humpback whales (Megaptera novaeangliae) in tropical waters off Brazil. Mar Mammal Sci.

2009 Apr;25(2):416-9.

725 25. Owen K, Warren J, Noad M, Donnelly D, Goldizen A, Dunlop R. Effect of prey type on the 726 fine-scale feeding behaviour of migrating east Australian humpback whales. Mar Ecol Prog 727 Ser [Internet]. 2015 Dec 15 [cited 2017 Nov 30];541:231-44. Available from: http://www.int728 res.com/abstracts/meps/v541/p231-244/

729 26. Eisenmann P, Fry B, Mazumder D, Jacobsen G, Holyoake CS, Coughran D, et al.

$730 \quad$ Radiocarbon as a Novel Tracer of Extra-Antarctic Feeding in Southern Hemisphere $731 \quad$ Humpback Whales. Sci Rep. 2017;7.

732 27. Owen K, Ailbhe Kavanagh BS, Joseph Warren BD, Michael Noad BJ, Donnelly D, Anne 733 Goldizen BW, et al. Potential energy gain by whales outside of the Antarctic: prey preferences 734 and consumption rates of migrating humpback whales (Megaptera novaeangliae). Polar Biol 735 [Internet]. 2016 [cited 2017 Nov 30];40. Available from:

736 https://link.springer.com/content/pdf/10.1007\%2Fs00300-016-1951-9.pdf

737 28. Gales N, Double MC, Robinson S, Jenner C, Jenner M, King E, et al. Satellite tracking of 738 southbound East Australian humpback whales (Megaptera novaeangliae ) : challenging the 739 feast or famine model for migrating whales. Int Whal Comm. 2009;

740 29. Robinson R, Crick H, Learmonth J, Maclean I, Thomas C, Bairlein F, et al. Travelling 741 through a warming world: climate change and migratory species. Endanger Species Res 742 [Internet]. 2009 Jun 17 [cited 2017 Dec 1];7(2):87-99. Available from: http://www.int743 res.com/abstracts/esr/v7/n2/p87-99/

744 30. Grantham HS, Bode M, McDonald-Madden E, Game ET, Knight AT, Possingham HP. 745 Effective conservation planning requires learning and adaptation. Front Ecol Environ 746 [Internet]. 2010 Oct 1 [cited 2017 Dec 1];8(8):431-7. Available from: 
http://doi.wiley.com/10.1890/080151

748 31. Martin TG, Chadès I, Arcese P, Marra PP, Possingham HP, Norris DR. Optimal Conservation of Migratory Species. Jones P, editor. PLoS One [Internet]. 2007 Aug 15 [cited

32. Heide-Jorgensen MP, Kleivane L, Oien N, Laidre KL, Jensen MV. A New Technique for Deploying Satellite Transmitters on Baleen Whales: Tracking a Blue Whale (Balaenoptera Musculus) in the North Atlantic. Mar Mammal Sci [Internet]. 2001 Oct 1 [cited 2020 Mar 25];17(4):949-54. Available from: http://doi.wiley.com/10.1111/j.1748-7692.2001.tb01309.x

33. Palsbøll PJ. Sampling of Skin Biopsies from Free-Raging Large Cetaceans in West Greenland: Development of new Biopsy Tips and Bolt Designs. Int Whal Comm Spec Issue Ser [Internet]. 1991 [cited 2018 Sep 29];(13). Available from:

34. Katona SK, Whitehead HP. Identifying Humpback Whales using their natural markings. Polar Rec (Gr Brit) [Internet]. 1981 May 27 [cited 2019 Oct 17];20(128):439_44. Available from:

764 35. Sambrook J, Fritsch EF, Maniatis T. Molecular cloning: a laboratory manual. Mol cloning a Lab manual [Internet]. 1989 [cited 2017 Dec 19];(Ed. 2). Available from: endocrine pregnancy test for humpback whales. Conserv Physiol [Internet]. 2018 Jun 1 [cited 2018 Sep 29];6(1). Available from: 
771 37. Kahle D, Wickham H. ggmap: Spatial Visualization with ggplot2. R J [Internet]. 2013 [cited 2019 Oct 17];5. Available from: https://pdfs.semanticscholar.org/79da/0d9d7d828169db3084024a4acf6c259d0c74.pdf

774 38. Kraska J, Crespo GO, Johnston DW. Bio-logging of marine migratory species in the law of 775 the sea. Mar Policy [Internet]. 2015 Jan 1 [cited 2019 Jun 24];51:394-400. Available from: https://www.sciencedirect.com/science/article/pii/S0308597X14002322

777 39. Gerrodette T. Inference without significance: measuring support for hypotheses rather than 778 rejecting them. Mar Ecol [Internet]. 2011 Sep [cited 2020 Jan 18];32(3):404-18. Available from: http://doi.wiley.com/10.1111/j.1439-0485.2011.00466.x

780 40. Wasserstein RL, Lazar NA. The American Statistician The ASA's Statement on p-Values: 781 Context, Process, and Purpose. 2016 [cited 2020 Jan 18]; Available from: http:/ / amstat.tandfonline.com/action/journalInformation?journalCode=utas20

783 41. Bestley S, Jonsen ID, Hindell MA, Guinet C, Charrassin J-B. Integrative modelling of animal 784 movement: incorporating in situ habitat and behavioural information for a migratory marine 785 predator. Proceedings Biol Sci [Internet]. 2013 Jan 7 [cited 2017 Dec 20];280(1750):20122262.

787 42. Jonsen ID, Flemming JM, Myers RA. Robust State-Space Modeling of Animal Movement 788 Data. Ecology [Internet]. 2005 Nov 1 [cited 2017 Dec 19];86(11):2874-80. Available from:

790 43. Friedlaender A, Tyson R, Stimpert A, Read A, Nowacek D. Extreme diel variation in the 791 feeding behavior of humpback whales along the western Antarctic Peninsula during autumn.

794 44. Jonsen ID, Myers RA, James MC. Identifying leatherback turtle foraging behaviour from 
satellite telemetry using a switching state-space model. Mar Ecol Prog Ser. 2007 May $14 ; 337: 255-64$.

797 45. Hays GC, Ferreira LC, Sequeira AMM, Meekan MG, Duarte CM, Bailey H, et al. Key

798 Questions in Marine Megafauna Movement Ecology. Trends Ecol Evol [Internet]. 2016 Jun 1

$799 \quad$ [cited 2018 Apr 28];31(6):463-75. Available from:

800 http://www.ncbi.nlm.nih.gov/pubmed/26979550

801 46. Gelman A, Hill J. Data Analysis Using Regression and Multilevel/Hierarchical Models. Data 802 Analysis Using Regression and Multilevel/Hierarchical Models. Cambridge University Press; 8032006.

804 47. Gibbons J, Capella JJ, Valladares C. Rediscovery of a humpback whale (Megaptera 805 novaeangliae) feeding ground in the Straits of Magellan, Chile.

806 48. Hucke-Gaete R, Haro D, Torres-Florez JP, Montecinos Y, Viddi F, Bedriñana-Romano L, et 807 al. A historical feeding ground for humpback whales in the eastern South Pacific revisited: the 808 case of northern Patagonia, Chile. Aquat Conserv Mar Freshw Ecosyst [Internet]. 2013 Dec 1 [cited 2020 Jul 4];23(6):858-67. Available from: http://doi.wiley.com/10.1002/aqc.2343

810 49. Andrews-Goff V, Bestley S, Gales NJ, Laverick SM, Paton D, Polanowski AM, et al.

811 Humpback whale migrations to Antarctic summer foraging grounds through the southwest 812 Pacific Ocean. Sci Rep. 2018 Dec 1;8(1):1-14.

813 50. Eken G, Bennun L, Brooks TM, Darwall W, Fishpool LDC, Foster M, et al. Key Biodiversity 814 Areas as Site Conservation Targets. Bioscience [Internet]. 2004 Dec 1 [cited 2017 Dec 815 1];54(12):1110-8. Available from:

816 https://academic.oup.com/bioscience/article/54/12/1110/329687

817 51. di Sciara GN, Hoyt E, Reeves R, Ardron J, Marsh H, Vongraven D, et al. Place-based 818 approaches to marine mammal conservation. Aquat Conserv Mar Freshw Ecosyst [nternet]. 
821 52. MiCO: Migratory Connectivity in the Ocean [Internet]. [cited 2019 Jun 24]. Available from:

\section{$827 \quad$ Figure Titles and Legends}

828

Table 1: Summary of northward migrations for 16 whales fitted with satellite-linked telemetry

830 tags

831

832 Table 2: Percentage of migratory time in national waters off the coast of South America by

833 satellite tagged humpback whales

834

835 Figure 1: Satellite-linked tracks of humpback whales satellite tagged off of the WAP by A) Year B) Density C) Sex \& Reproductive Status

Figure 2: Migratory movements of individual humpback whales satellite-tagged off the Western

839 Antarctic Peninsula during austral summer/fall 2012-2017 
841 Figure 3: Average speeds of humpback whales by segment of migratory route

843 Figure 4: ARS, traveling, and unknown behavior exhibited by satellite tagged humpback whales

844 on their northward migration from Antarctica

845

Table 1: Summary of northward migrations for 16 whales fitted with satellite-linked telemetry tags

\begin{tabular}{|c|c|c|c|c|}
\hline Ptt & $\begin{array}{c}\text { Sex/ } \\
\text { Pregnancy } \\
\text { Status }\end{array}$ & Start of N Migration & $\begin{array}{c}\text { End of N } \\
\text { Migration }\end{array}$ & $\begin{array}{c}\text { Duration of Migration } \\
\text { Tracked (days) }\end{array}$ \\
\hline 121210 & Male & $4 / 30 / 13$ & $6 / 23 / 13$ & 54 \\
\hline 131130 & $\begin{array}{l}\text { Female (not } \\
\text { pregnant) } \\
\text { resting }\end{array}$ & $4 / 27 / 16$ & $6 / 20 / 16$ & 54 \\
\hline 123232 & Unknown & $4 / 25 / 13$ & $6 / 14 / 13$ & 50 \\
\hline 112699 & Unknown & $6 / 15 / 12$ & $8 / 1 / 12$ & 47 \\
\hline 166123 & Male & $6 / 14 / 17$ & $7 / 25 / 17$ & 41 \\
\hline 131132 & Male & $5 / 9 / 16$ & NA & 36 \\
\hline 123224 & $\begin{array}{c}\text { Female } \\
\text { (pregnant-NL) }\end{array}$ & $5 / 23 / 13$ & NA & 34 \\
\hline 166128 & $\begin{array}{c}\text { Female } \\
\text { (Pregnant-NL) }\end{array}$ & $5 / 18 / 17$ & NA & 32 \\
\hline 121207 & $\begin{array}{l}\text { Female (not } \\
\text { pregnant - } \\
\text { resting) }\end{array}$ & $5 / 7 / 13$ & NA & 26 \\
\hline 131133 & Male & $7 / 5 / 16$ & NA & 26 \\
\hline 131136 & Unknown & $6 / 30 / 16$ & NA & 23 \\
\hline 131127 & Unknown & $7 / 15 / 16$ & NA & 21 \\
\hline 166126 & $\begin{array}{c}\text { Female (NP - } \\
\text { juvenile- } \\
\text { resting) }\end{array}$ & $7 / 1 / 17$ & NA & 19 \\
\hline 166122 & $\begin{array}{c}\text { Female } \\
\text { (Pregnant -NL) }\end{array}$ & $6 / 18 / 17$ & NA & 14 \\
\hline 123236 & $\begin{array}{l}\text { Female (not } \\
\text { pregnant- } \\
\text { resting) }\end{array}$ & $3 / 16 / 13$ & NA & 11 \\
\hline
\end{tabular}




\begin{tabular}{|l|c|c|c|c}
166125 & $\begin{array}{c}\text { Female } \\
\text { (Pregnant-NL) }\end{array}$ & $6 / 5 / 17$ & NA & 10
\end{tabular}

851 Table 1 continued

\begin{tabular}{|c|c|c|c|c|}
\hline $\mathbf{P t t}$ & $\begin{array}{c}\text { \# of } \\
\text { transmissions } \\
\text { during } \\
\text { migration }\end{array}$ & $\begin{array}{c}\text { Great Circle (GC) } \\
\text { Distance of tracked } \\
\text { migration } \mathbf{( k m )}\end{array}$ & $\begin{array}{c}\text { GC speed } \\
\mathbf{( k m / h r )}\end{array}$ & $\begin{array}{c}\text { Average Speed during } \\
\text { migration } \mathbf{( k m} / \mathbf{h r})\end{array}$ \\
\hline $\mathbf{1 2 1 2 1 0}$ & 906 & 6652 & 5.1 & 5.5 \\
\hline $\mathbf{1 3 1 1 3 0}$ & 555 & 6714 & 5.1 & 5.4 \\
\hline $\mathbf{1 2 3 2 3 2}$ & 68 & 6640 & 5.5 & 5.8 \\
\hline $\mathbf{1 1 2 6 9 9}$ & 342 & 6654 & 5.5 & 5.8 \\
\hline $\mathbf{1 6 6 1 2 3}$ & 548 & 6532 & 6.6 & 6.9 \\
\hline $\mathbf{1 3 1 1 3 2}$ & 659 & 5195 & 5.8 & 6.1 \\
\hline $\mathbf{1 2 3 2 2 4}$ & 172 & 5411 & 6.3 & 6.6 \\
\hline $\mathbf{1 6 6 1 2 8}$ & 384 & 4354 & 5.6 & 5.9 \\
\hline $\mathbf{1 2 1 2 0 7}$ & 347 & 5113 & 4.6 & 6.7 \\
\hline $\mathbf{1 3 1 1 3 3}$ & 222 & 4117 & 6.5 & 6.8 \\
\hline $\mathbf{1 3 1 1 3 6}$ & 141 & 4244 & 6.6 & 6.9 \\
\hline $\mathbf{1 3 1 1 2 7}$ & 161 & 3296 & 6.2 & 7.3 \\
\hline $\mathbf{1 6 6 1 2 6}$ & 204 & 3413 & 6.6 & 5.7 \\
\hline $\mathbf{1 6 6 1 2 2}$ & 190 & 1921 & 5.2 & 1.7 \\
\hline $\mathbf{1 2 3 2 3 6}$ & 231 & 379 & 6.2 & 6.3 \\
\hline $\mathbf{1 6 6 1 2 5}$ & 168 & 1508 & 6.7 & \\
\hline
\end{tabular}

\begin{tabular}{|c|c|c|c|c|c|}
\hline Ptt & $\begin{array}{c}\text { Average } \\
\text { Speed } \\
\text { WAP- } \\
\text { Cape } \\
\text { Horn } \\
(\mathbf{k m} / \mathbf{h r})\end{array}$ & $\begin{array}{c}\text { Average Speed } \\
\text { Cape Horn - } \\
\text { Peninsula de } \\
\text { Paracas } \\
(\mathbf{k m} / \mathbf{h r})\end{array}$ & $\begin{array}{l}\text { Average Speed } \\
\text { Peninsula de } \\
\text { Paracas- Zona } \\
\text { Reserverda } \\
\text { Illescas } \\
(\mathbf{k m} / \mathrm{hr})\end{array}$ & $\begin{array}{l}\text { Average Speed } \\
\text { Zona } \\
\text { Reserverda } \\
\text { Illescas \& above } \\
\text { (km/hr) }\end{array}$ & $\begin{array}{l}\text { Completed } \\
\text { Migration? }\end{array}$ \\
\hline 121210 & 3.6 & 6 & 6.5 & 2 & Yes \\
\hline
\end{tabular}




\begin{tabular}{|l|c|c|c|c|c|}
\hline $\mathbf{1 3 1 1 3 0}$ & 5.4 & 5.2 & 7.2 & 2.5 & Yes \\
\hline $\mathbf{1 2 3 2 3 2}$ & 4.7 & 6.2 & 3.8 & 3 & Yes \\
\hline $\mathbf{1 1 2 6 9 9}$ & 4.9 & 6.4 & 4.4 & 3.4 & Yes \\
\hline $\mathbf{1 6 6 1 2 3}$ & 8 & 7.4 & 4.9 & 3.4 & Yes \\
\hline $\mathbf{1 3 1 1 3 2}$ & 5.6 & 6.3 & NA & NA & No \\
\hline $\mathbf{1 2 3 2 2 4}$ & 6.3 & 6.7 & NA & NA & No \\
\hline $\mathbf{1 6 6 1 2 8}$ & 5.4 & 6 & NA & NA & No \\
\hline $\mathbf{1 2 1 2 0 7}$ & 5.9 & 4.4 & NA & NA & No \\
\hline $\mathbf{1 3 1 1 3 3}$ & 5.6 & 7.1 & NA & NA & No \\
\hline $\mathbf{1 3 1 1 3 6}$ & 7.2 & 6.7 & NA & NA & No \\
\hline $\mathbf{1 3 1 1 2 7}$ & 6.1 & 7.2 & NA & NA & No \\
\hline $\mathbf{1 6 6 1 2 6}$ & 5.7 & 8.5 & NA & NA & No \\
\hline $\mathbf{1 6 6 1 2 2}$ & 5.6 & 5.8 & NA & NA & No \\
\hline $\mathbf{1 2 3 2 3 6}$ & 1.7 & NA & NA & NA & NA \\
\hline $\mathbf{1 6 6 1 2 5}$ & 6 & 7.3 & NA & & N \\
\hline
\end{tabular}


Figures
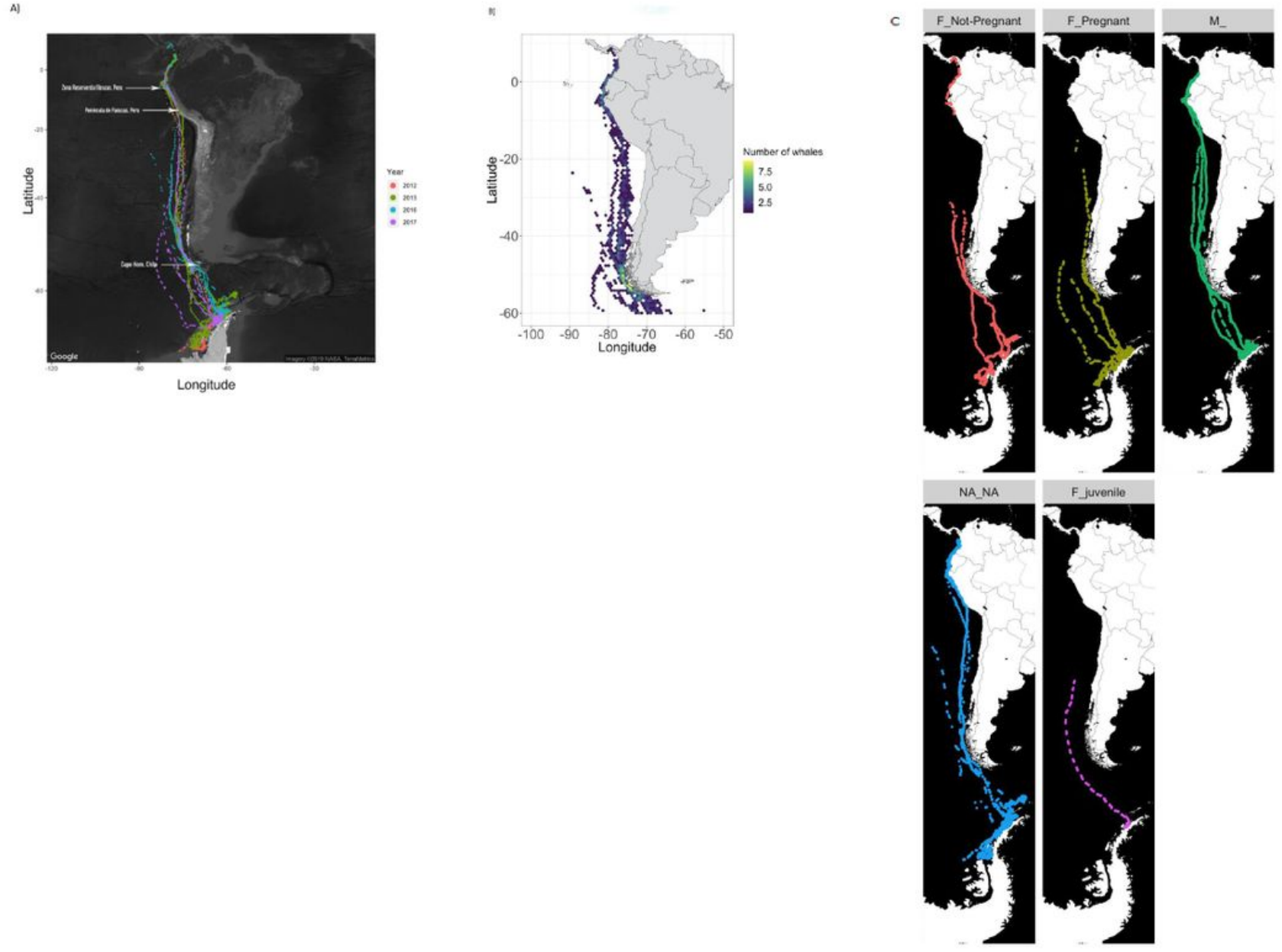

Figure 1

Satellite-linked tracks of humpback whales satellite tagged off of the WAP by A) Year B) Density C) Sex \& Reproductive Status 


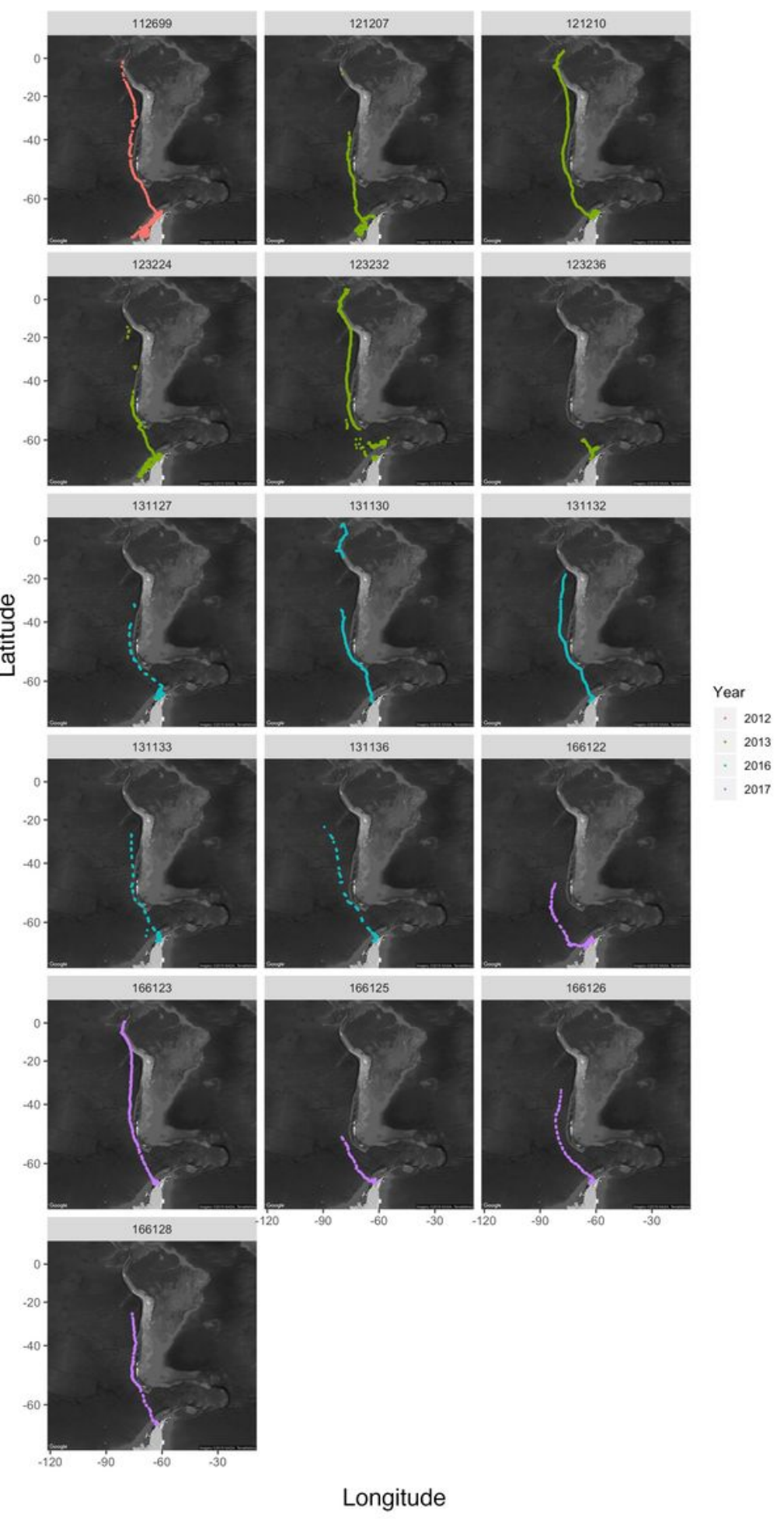

Figure 2

Migratory movements of individual humpback whales satellite-tagged off the Western Antarctic Peninsula during austral summer/fall 2012-2017 


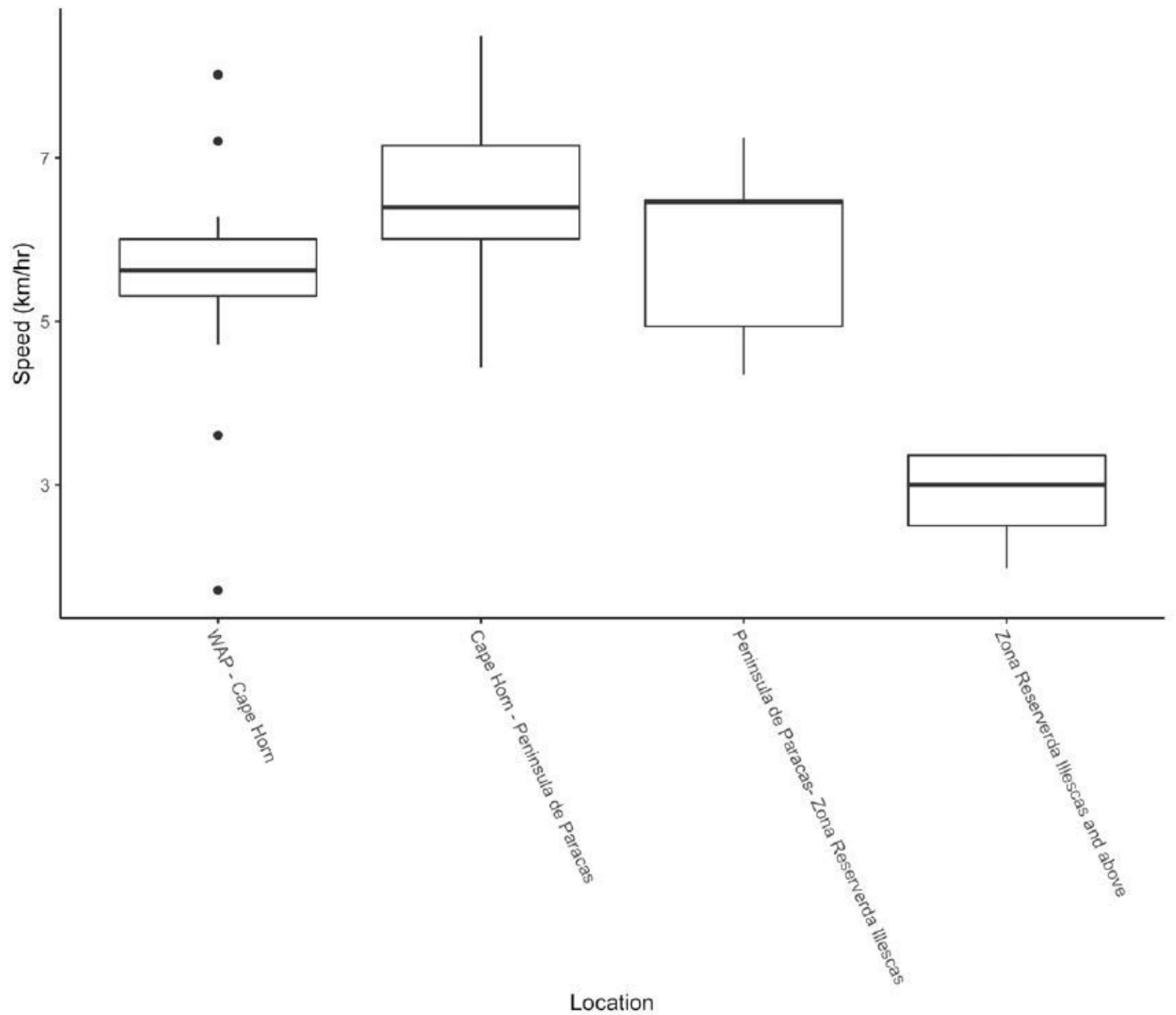

Figure 3

Average speeds of humpback whales by segment of migratory route 


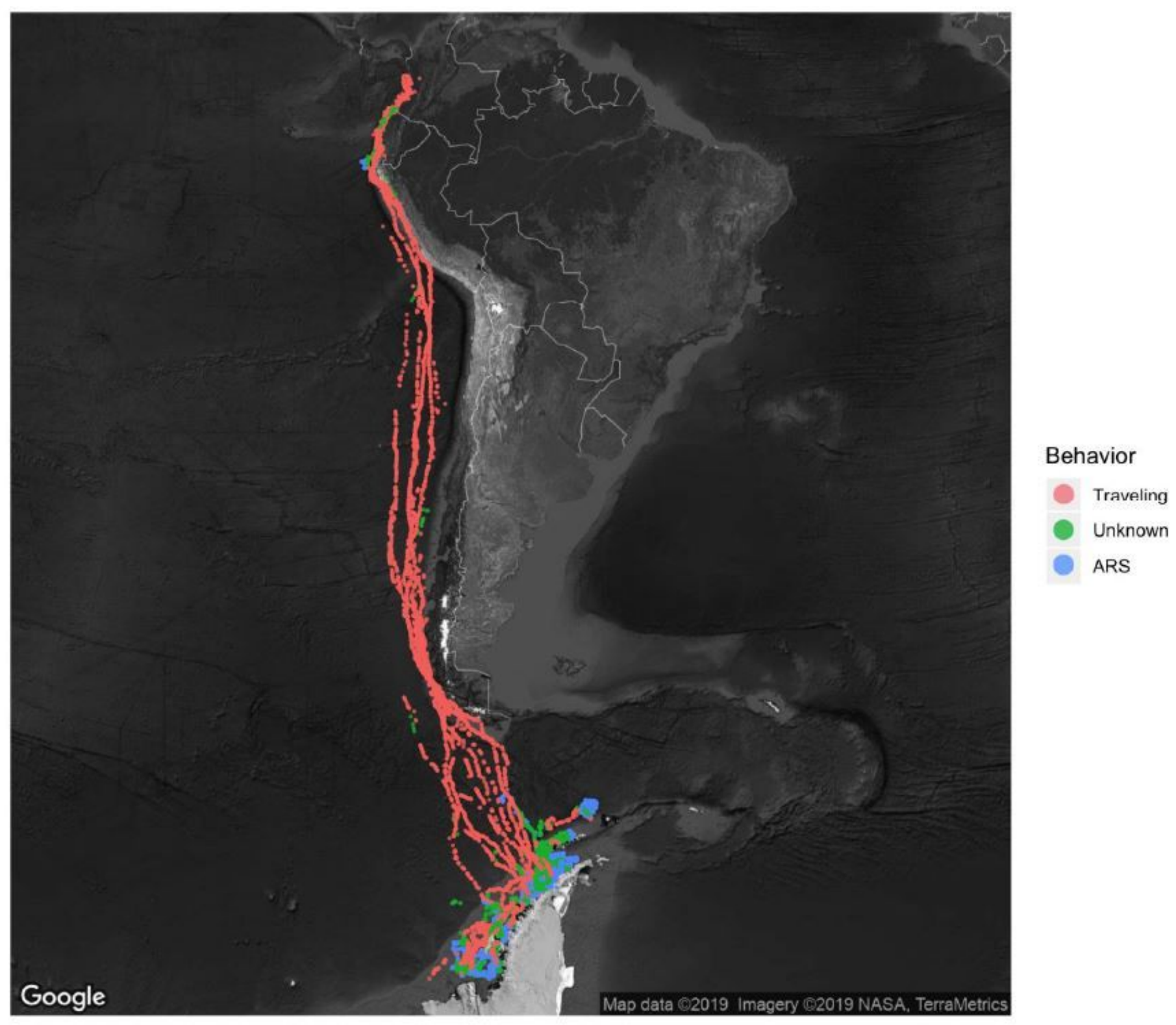

\section{Figure 4}

ARS, traveling, and unknown behavior exhibited by satellite tagged humpback whales on their northward migration from Antarctica 